\title{
Empathie kann auch schädlich sein!
}

\author{
Empathie gilt gemeinhin als Garant für eine menschliche Medizin. Doch nichts ist immer nur \\ gut. So kann auch Empathie manchmal schädlich sein, und zwar sowohl für den Patienten als \\ auch für den Arzt.
}

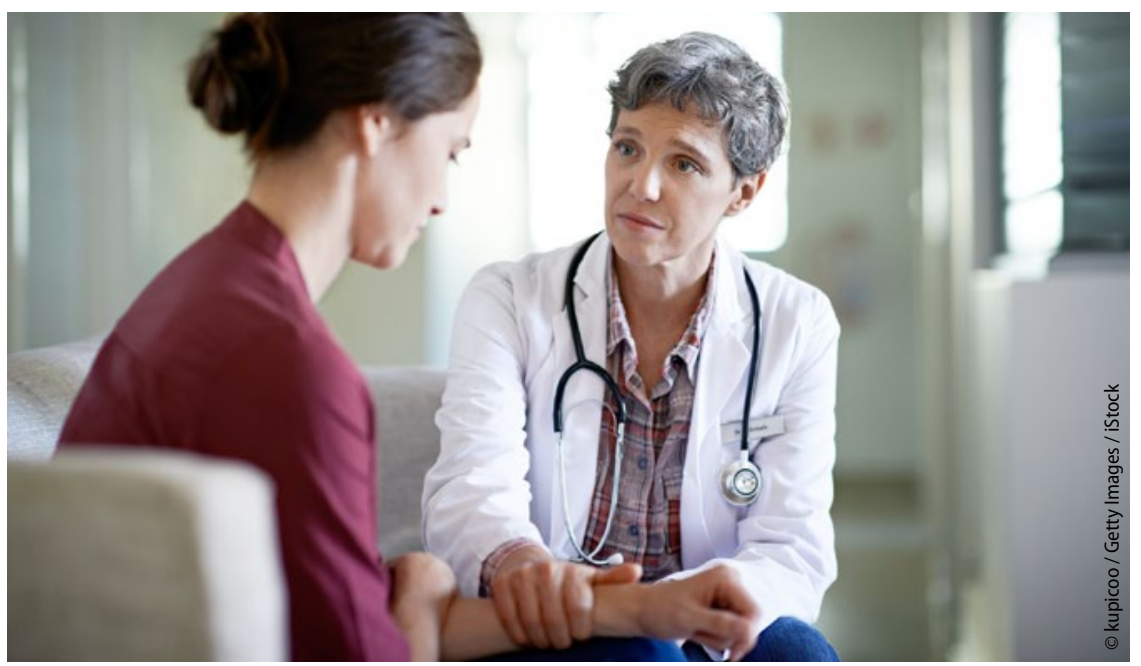

Einfühlsam bis zur Selbstaufgabe?

_ In der modernen Technik-basierten Medizin bleibt zu wenig Raum für Empathie. So lautet ein weitverbreiterter und sicherlich nicht ganz unberechtigter Vorwurf. Für die Ärzte seien Algorithmen heute wichtiger als Zuwendung, heißt es. Doch was bedeutet eigentlich Empathie? „Darunter versteht man die Fähigkeit, die Sichtweise des anderen zu verstehen und dies dann so einfühlsam zu kommunizieren, dass es für ihn hilfreich ist", erklärte Prof. Alexander Kiss vom Universitätsspital Basel. Schon der angehende Arzt müsse lernen, dass empathisch zu sein nicht nur bedeute, „zuhören zu können“. Empathie heißt vielmehr, Fragen zu stellen, die dann Antworten hervorbringen, die man anhören muss. Empathie bedarf des beharrlichen Nachfragens genauso wie des Vorstellungsvermögens und des Wissens um die eigene Unwissenheit. Empathie heißt, dass man sich klar macht: Es gibt immer einen Kontext, dessen Umriss mehr umfasst als das, was gerade noch sichtbar ist.

\section{Problemlösung erfordert Distanz}

Studien haben gezeigt, dass die Fähigkeit zur Empathie mit der Dauer der Berufstätigkeit abnimmt. Es kommt zu einer Habituation an den Schmerz und das Leid anderer, der Arzt lernt, sich davon zu distanzieren. Dies ist eine unabdingbare Voraussetzung für das ,richtige problemorientierte Planen“. Plakativ könnte man formulieren: Empathie erfordert Nähe, Problemlösung aber Distanz. „Die ärztliche Kunst besteht darin, zwischen beidem oszillieren zu können“, sagte Kiss. Eine zu große emotionale Nähe zum Patienten erschwere es, die fachlich richtige Entscheidung zu treffen. Deshalb sollten Ärzte Angehörige und enge Freunde nicht behandeln: „Sonst besteht die Gefahr der Überoder Unterversorgung“, so Kiss.

\section{Der Patient erwartet mehr als Mitgefühl}

Auch der Patient erwartet nicht nur Empathie, sondern auch den kühlen Kopf des Arztes, den dieser braucht, um das

\section{Dem Arzt droht ein Burn-out}

„Ärzte, die nicht die richtige Balance zwischen Empathie und professioneller Distanz finden, haben ein erhöhtes Risiko für ein Burn-out-Syndrom", so Kiss. Es droht die emotionale Erschöpfung, der Arzt fühlt sich verbraucht. Ein solches Burn-out führt dann zur Depersonalisation, d.h. der Arzt wird abgestumpfter, ja sogar zynisch. Und dies wird eine vertrauensvolle Arzt-Patienten-Beziehung gefährden oder sogar zerstören.

„Richtige zu tun“. So kann es durchaus passieren, dass der Patient auf die Frage des Arztes „Wie geht es Ihnen heute?" mit der Gegenfrage antwortet: „Und wie geht es jetzt weiter mit mir?" Damit will der Patient andeuten, dass ihm im Moment die Information über die weitere Therapie wichtiger ist als die einfühlsame Zuwendung.

„Problematisch wird es dann, wenn der Arzt seine Einfühlung und sein Mitgefühl wiederholt äußert, obwohl der Patient nicht darüber reden möchte“, erklärte Kiss. Ein solches Verhalten werde vom Patienten als unangenehmes „Bohren" empfunden.

Wenn Arzt und Patient eine unterschiedliche Agenda haben, also der Arzt Empathie zeigen will, der Patient aber gerade eine sachorientierte Beratung wünscht, besteht die Gefahr, dass sie aneinander vorbeireden. Und für den Patienten kann es letztendlich auch schädlich sein, wenn der Arzt zu wissen glaubt, wie es dem Patienten geht, er aber tatsächlich seine eigene Welt auf den Patienten projiziert. „Dann wird Projektion zu einem schädlichen Abwehrmechanismus", so Kiss.

Dr. Peter Stiefelhagen

- Quelle: medArt, 24.6.2016 in Basel 